\title{
PEMODELAN STRUKTURAL DARI EMOSI POSITIF SEBAGAI PEMEDIASI TERHADAP PEMBELIAN TIDAK TERENCANA
}

\author{
Ni Wayan Arni Yanita ${ }^{\S 1}$, Ketut Jayanegara ${ }^{2}$, I Putu Eka Nila Kencana ${ }^{3}$ \\ ${ }^{1}$ Jurusan Matematika, Fakultas MIPA - Universitas Udayana [Email: arniyanita.ay@ gmail.com] \\ ${ }^{2}$ Jurusan Matematika, Fakultas MIPA - Universitas Udayana [Email: ketut_jayanegara@yahoo.com] \\ ${ }^{3}$ Jurusan Matematika, Fakultas MIPA - Universitas Udayana [Email: i.putu.enk@gmail.com] \\ ${ }^{\S}$ Corresponding Author
}

\begin{abstract}
Latent variables are variables that can not be observed directly. Latent variables can be observed with constituent indicators. One of the methods used to analyze the latent variables are Structural Equation Modeling (SEM). This research raised the case of impulse buying to be applied to the SEM method. Impulse buying influenced by the characteristics of the hypermarket, situational factors, the characteristics of the product, promotion and positive emotions. The purpose of this research was to determine the effect dari positive emotions as mediation to impulse buying.The results obtained indicate that positive emotions directly affect the impulse buying of 0.302, promotion directly affects the positive emotions of 0.367 , and the promotion of indirect effect to impulse buying of 0.111 . So positive emotions can mediate to impulse buying of 0.020. Goodness of fit mediation models not good with value 0.39 .
\end{abstract}

Keywords: Laten Variable, Structural Equation Modelling (SEM), Mediation, Impulse Buying

\section{PENDAHULUAN}

Variabel yang menjadi acuan dalam penelitian tidak selalu merupakan variabel yang dapat diamati secara langsung, namun ada variabel yang tidak dapat diamati secara langsung. Variabel yang tidak dapat diamati secara langsung dikenal dengan variabel laten. Dalam suatu analisis yang menggunakan variabel laten, pengaruh variabel tersebut dapat diamati melalui indikator penyusun variabel laten. Ada banyak metode analisis yang dapat digunakan untuk mengamati variabel laten salah satunya yang paling populer adalah Structural Equation Modeling (SEM).

SEM merupakan gabungan dari analisis faktor dan analisis regresi. Analisis faktor direpresentasikan pada model pengukuran SEM, sedangkan analisis regresi direpresentasikan pada model struktural SEM. Model pengukuran (measurement) digunakan untuk mengukur seberapa kuat variabel indikator dapat menjelaskan variabel laten.
Model struktural digunakan untuk mengukur seberapa kuat variabel-variabel laten saling mempengaruhi.

Pola hubungan yang terdapat dalam SEM meliputi hubungan langsung (direct effect) dan hubungan tidak langsung (indirect effect). Hubungan langsung terjadi jika satu variabel laten mempengaruhi variabel laten lainnya tanpa adanya variabel laten ketiga yang memediasi hubungan kedua variabel, sedangkan hubungan tidak langsung adalah jika ada variabel laten ketiga yang memediasi hubungan kedua variabel [1]. Variabel mediasi bersifat sebagai perantara atau penghubung variabel laten yang berperan sebagai variabel bebas (variabel eksogen) terhadap variabel laten yang berperan sebagai variabel terikat (variabel endogen).

Penelitian mengenai structural equation modelling yang dilakukan oleh Karbasivar dan Yarahmadi [2] menyatakan bahwa terdapat pengaruh antara kegiatan promosi pada ritel 
modern seperti diskon dan pemberian produk gratis terhadap pembelian tidak terencana. Tinne [3] mengklasifikasikan beberapa faktor yang mempengaruhi proses pembelian tidak terencana, yaitu karakteristik toko, faktor situasional dan karakteristik produk. Hasil penelitian Rachmawati [4] menyatakan emosi positif berpengaruh terhadap pembelian tidak terencana. Pada penelitian yang dilakukan oleh Kurniawan dan Kunto [5] diperoleh bahwa promosi pada Matahari department store cabang Surabaya memberikan pengaruh emosi positif dalam berbelanja. Sehingga dari pola hubungan langsung antara karakteristik toko, faktor situasional, karakteristik produk, promosi, emosi positif dan pembelian tidak terencana dapat dibentuk pola hubungan tidak langsung, dengan emosi positif sebagai mediasi. Proses pembelian tidak terencana terjadi di tempat belanja, salah satunya hypermarket yang menawarkan sistem one stop shopping.

Berdasarkan uraian di atas penulis ingin mengetahui bagaimana pengaruh karakteristik hypermarket, faktor situasional, karakteristik produk, promosi, emosi positif terhadap pembelian tidak terencana, pengaruh karakteristik hypermarket, faktor situasional, karakteristik produk, promosi terhadap emosi positif, pengaruh emosi positif sebagai pemediasi terhadap pembelian tidak terencana. Variabel laten karakteristik hypermarket, faktor situasional, karakteristik produk, promosi, emosi positif, dan pembelian tidak terencana dapat diukur dengan indikator-indikator penjelasnya.

\section{METODE PENELITIAN}

Data yang digunakan dalam penelitian ini adalah data primer yang diperoleh secara langsung dari konsumen hypermarket dengan menggunakan kuesioner. Jumlah sampel penelitian yang digunakan 200 sampel diambil dari seluruh konsumen yang melakukan pembelanjaan dihypermarket.

Penelitian ini terdiri dari 7 variabel laten yaitu : 1. variabel laten pengaruh, 2. variabel laten karakteristik hypermarket, 3. variabel laten faktor situasional, 4. variabel laten karakteristik produk, 5. variabel laten promosi, 6. variabel laten emosi positif, 7. variabel laten pembelian tidak terencana

Adapun rancangan model struktural yang digunakan dalam penelitian ini adalah sebagai berikut :

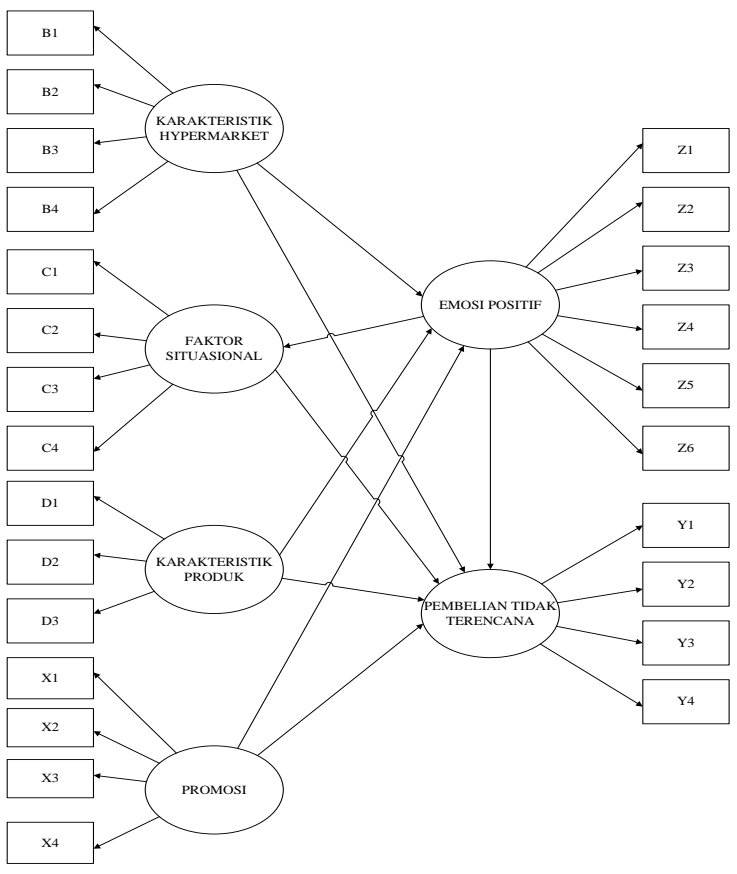

Gambar 1

Keterangan :

B1 : Konsumen tertarik dengan promosi yang ditawarkan oleh hypermarket

B2 : Pelayan di hypermarket dapat membantu dan menuntun konsumen dalam proses belanja

B3 : Suasana berbelanja di hypermarket membuat konsumen nyaman

B4 : Hypermarket memiliki ciri khas tertentu sehingga dapat dibedakan dengan tempat belanja lainnya

C1 : Waktu yang dibutuhkan saat berbelanja

C2 : Pendapatan per bulan

C3 : Alokasi belanja

C4 : Pendamping belanja

D1 : Konsumen membeli produk untuk sekedar memenuhi hasrat yang muncul

D2 : Konsumen membeli produk dengan mempertimbangkan fungsi dari suatu produk 
D3 : Konsumen membeli suatu produk ketika ada diskon

$\mathrm{X} 1$ : Konsumen tertarik membeli produk yang menawarkan diskon

X2 : Konsumen tertarik membeli produk beli 2 gratis 1

X3 : Konsumen melakukan pembelian di hypermarket ketika ada kegiatan yang menawarkan harga murah

X4 : Konsumen senang melakukan pembelian dengan kartu anggota

Z1 : Konsumen merasa nyaman berbelanja di hypermarket

Z2 : Konsumen merasa puas berbelanja di hypermarket

Z3 : Konsumen merasa senang berbelanja di hypermarket

Z4 : Konsumen suka berbelanja di hypermarket

Z4 : Konsumen tertarik berbelanja di hypermarket

Z6 : Konsumen bersemangat ketika berbelanja di hypermarket

Y1 : Konsumen melakukan pembelian secara spontan, ketika harga produk terjangkau

Y2 : Konsumen melakukan pembelian produk baru yang menarik minat sekedar memenuhi hasrat yang muncul

Y3 : Konsumen senang membeli produk diskon walaupun tidak direncanakan sebelumnya

Y4 : Konsumen melakukan pembelian produk lain, saat produk yang diinginkan habis / stok kosong

\section{HASIL DAN PEMBAHASAN}

Tahap awal analisis dilakukan dengan melakukan pengujian kelayakan instrumen penelitian atau pengujian validitas dan reliabilitas, dalam penelitian ini dilakukan terhadap kuesioner yang telah disebarkan sebanyak 30 ke konsumen hypermarket. Suatu item dalam instrument dinyatakan valid, apabila nilai koefisien korelasi antara item pertanyaan dengan skor total sebesar $\geq 0.30$ [6]. Selanjutnya, suatu instrument pengukuran yang digunakan dikatakan reliabel (dapat dipercaya) jika nilai Cronbach Alpha $\geq 0.60$ [6].

Selanjutnya untuk mengukur variabel karakteristik hypermarket digunakan 4 item pernyataan, variabel faktor situasional 4 item pertanyaan dan variabel karakteristik produk 3 item pernyataan. Ketiga variabel tersebut memiliki nilai korelasi lebih besar dari 0.3 dengan nilai alpha cronbach berturut-turut sebesar $0.850,0.766$, dan 0.675 .

Lain halnya pada variabel promosi yang memiliki 4 item pernyataan, dimana dari 4 item pernyataan tersebut terdapat 1 item pernyataan yang tidak valid yaitu nilai korelasi X4 $=0.280$ dengan nilai alpha cronbach sebesar 0.654. Berdasarkan survey di lapangan, peneliti melihat bahwa tidak semua konsumen melakukan pembelian dengan kartu anggota (X4), sehingga diputuskan X4 tidak digunakan di dalam model penelitian. Sedangkan variabel emosi positif yang diukur dengan 6 item pernyataan bernilai valid dengan alpha cronbach sebesar 0.720. Kemudian variabel pembelian tidak terencana terdiri dari 4 item pernyataan bernilai valid yaitu nilai korelasi $\mathrm{Y} 1=0.629, \mathrm{Y} 2=0.433, \mathrm{Y} 3=0.624, \mathrm{Y} 4=0.528$ dengan alpha cronbach sebesar 0.753 .

Memperhatikan dari total 25 item pernyataan pada kuesioner penelitian, hanya 1 item pernyataan yang dikeluarkan dari model yaitu item X4 dari variabel promosi.

Tahap selanjutnya setelah melakukan estimasi parameter adalah melakukan evaluasi pada outer model/measurement model dan inner model/structural model. Tujuan dari evaluasi pada model outer model dilakukan untuk menguji apakah estimasi parameter untuk masing-masing indikator signifikan atau tidak. Evaluasi pada outer model ini dilakukan dengan melihat nilai outer loading untuk indikator yang bersifat reflektif, sedangkan untuk indikator yang bersifat formatif dapat melihat nilai regression weight-nya.

Pada penelitian ini, pengukuran yang akan digunakan adalah outer loading untuk melihat hubungan variabel laten terhadap indkatornya. Sedangkan evaluasi pada inner model/structural model. bertujuan untuk 
melihat bagaimana hubungan antara variabel laten dengan variabel laten lainnya (inner model/structural model).

Adapun penduga-penduga untuk masingmasing jalur yang disajikan dalam Gambar 2 berikut:

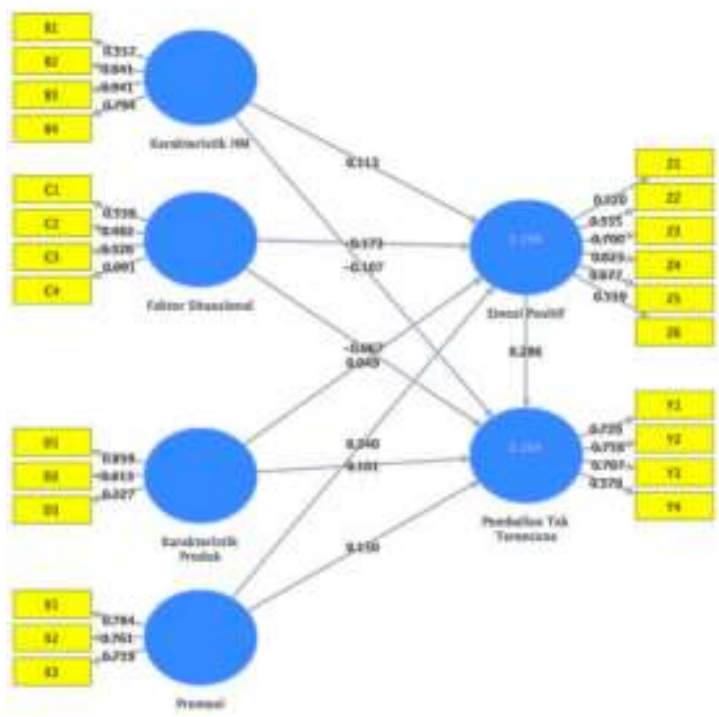

Gambar 2

SEM memiliki asumsi bahwa indikatornya harus bersifat reflektif. Indikator yang sifatnya reflektif dapat dilihat dari nilai faktor loading yang tidak terlalu jauh dengan indikator per variabel laten.

Gambar 2 menunjukkan Indikator B1 hanya mampu merefleksikan laten karakteristik hypermarket sebesar 0.317. Sedangkan indikator B2, B3, dan B4 berpengaruh signifikan dan nilai loading faktornya jauh lebih besar dari nilai B1. Sehingga untuk memperoleh indikator yang bersifat reflektif indikator B1 harus dikeluarkan dari model.

Selanjutnya indikator $\mathrm{C} 4$ memiliki nilai loading faktor lebih besar daripada indikator $\mathrm{C} 1, \mathrm{C} 2, \mathrm{C} 3$ yang hanya mampu merefleksikan faktor situasional sebesar $0.539,0.482,0.526$. sehingga indikator $\mathrm{C} 4$ harus dikeluarkan dari model agar terbentuk indikator yang bersifat reflektif. Begitu pula nilai loading faktor terkecil dimiliki oleh indikator D3 yaitu 0.327 dan tidak berpengaruh signifikan pada variabel laten karakteristik produk. Sehingga untuk memperoleh indikator yang bersifat reflektif indikator D3 harus dikeluarkan dari model.
Dari pengujian asumsi SEM yang indikatornya harus bersifat reflektif, diperoleh model penelitian setelah direduksi dengan penduga-penduga untuk masing-masing jalur digambarkan sebagai berikut :

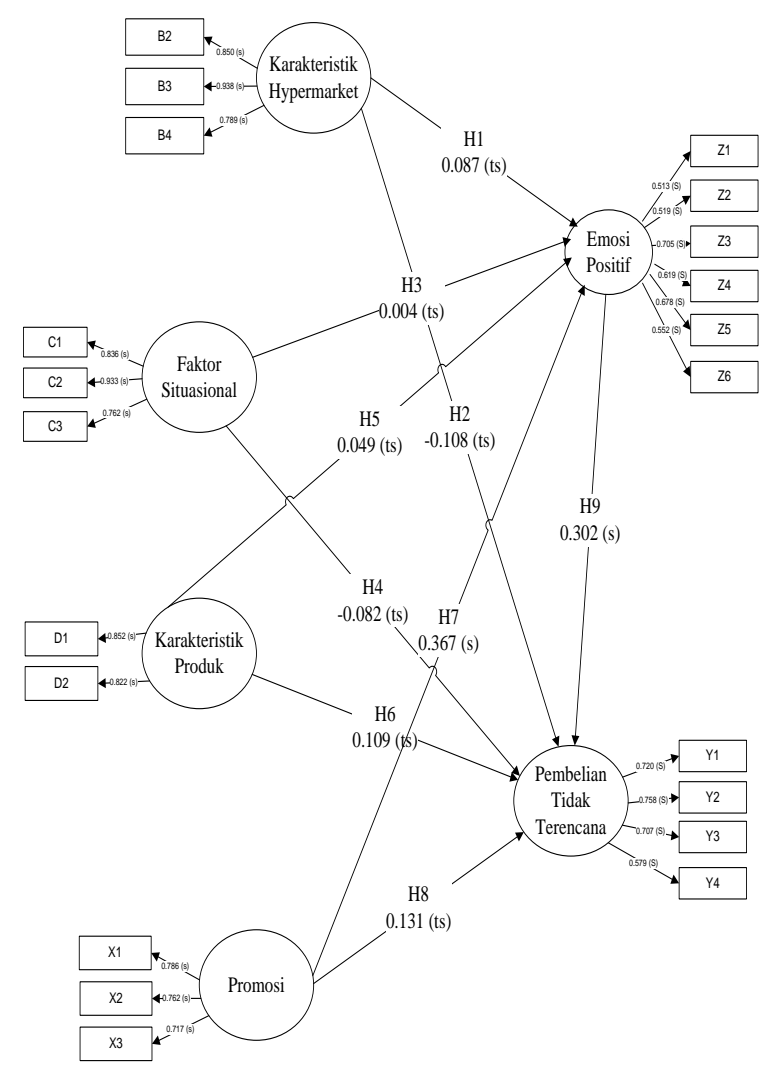

Gambar 3

Gambar 3 menunjukkan besar pengaruh indikator terhadap variabel laten dan pengaruh antar variabel laten. $s$ dan $t s$ menunjukkan signifikan dan tidak signifikannya pengaruh yang diberikan yang ditunjukkan pada model. Signifikan dan tidak signifikannya suatu besaran pengaruh dapat dilihat dari nilai $\mathrm{t}$ statistik yang dibandingkan terhadap t-tabel, dengan sampel 200 dan alpha 0.05 yaitu ttabel=1.97. Apabila t-statistik $<\mathrm{t}$-tabel maka pengaruh yang diberikan tidak signifikan. $\mathrm{R}^{2}$ menunjukkan besar keragaman yang dijelaskan oleh setiap variabel laten eksogen terhadap variabel laten endogennya.

Pada Gambar 3, dapat dilihat bahwa B2, B3, B4 signifikan sebagai refleksi dari karakteristik hypermarket dengan indikator B3 (suasana berbelanja di hypermarket membuat 
konsumen nyaman) memiliki nilai loading terbesar yaitu 0.938 dan indikator B4 (hypermarket memiliki ciri khas tertentu sehingga dapat dibedakan dengan tempat belanja lainnya) memiliki nilai loading terkecil yaitu 0.789 .

Sementara, pada variabel faktor situasional, indikator C1, C2, C3 mampu merefleksikan faktor situasional sebesar $0.539,0.482,0.526$. sedangkan pada variabel karakteristik produk, nilai loading factor dari kedua item yang menjelaskan laten karakteristik produk juga terefleksikan secara signifikan (t-statistik > t$\left.\operatorname{tabel}_{(0,05 ; 200)}=1.97\right)$. Gambar 3 menunjukan bahwa dibandingkan dengan item pernyataan D2 (membeli suatu produk karena mempertimbangkan fungsi dari produk tersebut) karakteristik produk lebih dominan terefleksikan pada indikator D1 yaitu membeli suatu produk untuk sekedar memenuhi hasrat yang muncul.

Kemudian pada Gambar 3 dapat dilihat variabel laten promosi dijelaskan oleh tiga indikator bersifat reflektif yaitu X1, X2, dan $X 3$. Sedangkan untuk variabel emosi positif direfleksikan oleh 6 indikator yaitu Z1, Z2, Z3, Z4, Z5, dan Z6. Z3 memiliki nilai loading terbesar diantara indikator-indikator lainnya yaitu 0.705 . Hal ini berarti bahwa emosi positif konsumen hypermarket dominan terefleksikan pada kesenangan saat berbelanja di hypermarket sudah baik.

Variabel pembelian tidak terencana direfleksikan oleh 4 indikator/item dengan keempat indikatornya signifikan pada taraf uji 5\%. Dibandingkan dengan indikator Y1, Y2, dan Y3, Y4 (Konsumen melakukan pembelian produk lain, saat produk yang diinginkan habis /stok kosong) memiliki nilai loading faktor terkecil yaitu 0.571

Tahap selanjutnya setelah evaluasi outer model adalah melakukan evaluasi inner model yang digunakan untuk menentukan hubungan antara variabel laten (konstruk). Hasil analisis yang diperoleh dengan software SmartPLS dapat dilihat pada Tabel 1.
Tabel 1. Nilai Path Coefficients pada Hubungan antara Variabel Laten

\begin{tabular}{|l|c|c|c|}
\hline \multicolumn{1}{|c|}{$\begin{array}{c}\text { Hubungan } \\
\text { Kausal }\end{array}$} & $\begin{array}{c}\text { Original } \\
\text { Sample }\end{array}$ & $\begin{array}{c}\text { Standart } \\
\text { Error }\end{array}$ & $\begin{array}{c}\text { T } \\
\text { statistics }\end{array}$ \\
\hline $\begin{array}{l}\text { Emosi Positif - } \\
\text { > Pembelian } \\
\text { Tak Terencana }\end{array}$ & 0.302 & 0.080 & 3.797 (s) \\
\hline $\begin{array}{l}\text { Faktor } \\
\text { Situasional } \\
\text {-> Emosi } \\
\text { Positif }\end{array}$ & 0.004 & 0.086 & 0.050 (ts) \\
\hline $\begin{array}{l}\text { Faktor } \\
\text { Situasional } \\
\text {-> Pembelian } \\
\text { Tak Terencana }\end{array}$ & -0.082 & 0.091 & 0.907 (ts) \\
\hline $\begin{array}{l}\text { Karakteristik } \\
\text { HM -> Emosi } \\
\text { Positif }\end{array}$ & 0.087 & 0.080 & 1.076 (ts) \\
\hline $\begin{array}{l}\text { Karakteristik } \\
\text { HM -> } \\
\text { Pembelian } \\
\text { Tak Terencana }\end{array}$ & -0.108 & 0.114 & 0.954 (ts) \\
\hline $\begin{array}{l}\text { Karakteristik } \\
\text { Produk -> } \\
\text { Emosi Positif }\end{array}$ & 0.049 & 0.087 & 0.569 (ts) \\
\hline $\begin{array}{l}\text { Karakteristik } \\
\text { Produk -> } \\
\text { Pembelian } \\
\text { Tak Terencana }\end{array}$ & 0.109 & 0.105 & 1.033 (ts) \\
\hline $\begin{array}{l}\text { Promosi -> } \\
\text { Emosi Positif }\end{array}$ & 0.367 & 0.068 & 5.403 (s) \\
\hline $\begin{array}{l}\text { Promosi -> } \\
\text { Pembelian } \\
\text { Tak Terencana }\end{array}$ & 0.131 & 0.081 & 1.612 (ts) \\
\hline Sumber: Data Pring & & & \\
\hline
\end{tabular}

Sumber: Data Primer (2014)

$$
\begin{aligned}
* \mathrm{~s} & =\text { signifikan } \\
\mathrm{ts} & =\text { tidak signifikan }
\end{aligned}
$$

Hasil pada Tabel 1 menyatakan bahwa hubungan kausal variabel laten faktor situasional dan karakteristik hypermarket terhadap pembelian tidak terencana bernilai negatif yaitu -0.082 dan -0.108 , sedangkan besaran pengaruh karakteristik produk dan promosi terhadap pembelian tidak terencana adalah 0.109 dan 0.131. Keempat variabel laten tersebut tidak berpengaruh signifikan terhadap 
pembelian tidak terencana, karena nilai tstatistik $<1.97$.

Sementara emosi positif dipengaruhi oleh empat variabel faktor situasional, karakteristik hypermarket, karakteristik produk, dan promosi dengan besaran pengaruh 0.004, 0.087, 0.049, dan 0.367. Dari empat variabel laten, yang signifikan berpengaruh terhadap emosi positif hanya variabel laten promosi dengan nilai signifikansi sebesar 5.403. Pembelian tidak terencana dipengaruhi oleh emosi positif sebesar 0.302, signifikan berpengaruh pada taraf uji 5\% (t-statistik > 1.97) yaitu sebesar 3.797.

\section{PENGUJIAN MEDIASI}

Sebagai salah satu syarat terjadinya proses mediasi maka pengaruh langsung variabel mediasi harus signifikan terhadap variabel endogen. Selanjutnya sebagai syarat pemediasi maka variabel eksogen harus signifikan pada variabel moderator sehingga dari keempat variabel eksogen hanya variabel laten promosi yang berpengaruh signifikan terhadap variabel emosi positif. Dari syarat-syarat tersebut maka akan dihasilkan model mediasi seperti gambar 3 berikut.

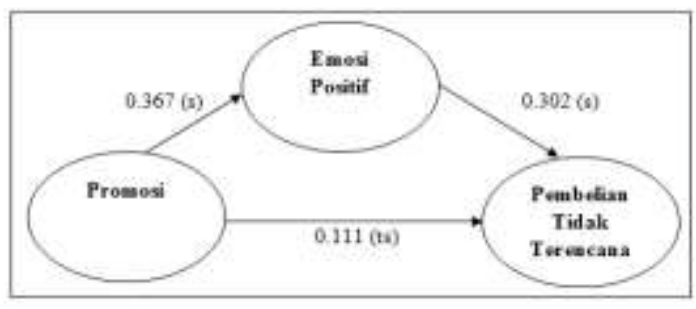

Gambar 4

Promosi berpengaruh signifikan terhadap emosi positif dengan nilai loading sebesar 0.367 , emosi positif mempengaruhi pembelian tidak terencana sebesar 0.302. Sedangkan promosi berpengaruh tidak langsung terhadap pembelian tidak terencana sebesar 0.111 memiliki pengaruh yang tidak signifikan.

Promosi berpengaruh langsung terhadap pembelian tidak terencana dengan nilai loading faktor sebesar 0.131. Wu dan Zumbo (2007) menyatakan bahwa besaran pengaruh tidak langsung diperoleh dari persamaan:

$$
c-c^{\prime}
$$

Sehingga promosi mempengaruhi pembelian tidak terencana dengan adanya variabel mediasi emosi positif sebesar 0.020 .

\section{KESIMPULAN}

Dari variabel karakteristik hypermarket, faktor situasional, karakteristik produk dan promosi, hanya promosi yang berpengaruh signifikan terhadap emosi positif konsumen

Dari variabel karakteristik hypermarket, faktor situasional, karakteristik produk, promosi serta emosi positif, variabel promosi dan emosi positif memberikan pengaruh terhadap pembelian tidak terencana

Emosi positif sebagai pemediasi berpengaruh terhadap pembelian tidak terencana

\section{DAFTAR PUSTAKA}

[1] Ghozali, I. (2001). Aplikasi Analisis Multivariate dengan Program SPSS Edisi 1. Semarang: Badan Penerbit Universitas Diponegoro.

[2] Karbasivar, A., \& Yarahmadi, H. (2011). Evaluating Effective Factors on Consumer Impulse Buying Behavior. Asian Journal of Business Management Studies 2, 174-181.

[3] Tinne, Wahida Shahan. 2010. Impulse Purchasing: A Literature Overview.Bangladesh. ASA University Review,Vol. 4. 2.

[4] Rachmawati, V. (2009). Hubungan Antara Hedonic Shopping Value, Positive Emotion, Dan Perilaku Impulse Buying Pada Konsumen Ritel. Jurnal Majalah Ekonomi, XIX(2), 192-208.

[5] Kurniawan, Denny \& Kunto Yohanes Sondang. (2013). Pengaruh Promosi dan Store AtmosphereTerhadap Impulse Buying Dengan Shopping Emotion Sebagai Variabel Intervening Studi Kasus di Matahari Department Store Cabang Supermall Surabaya. Jurnal Manajemen Pemasaran Petra, Vol.1, 1-8.

[6] Yusoff, Muhamad Saiful Bahri. (2011). Reliability and validity of the adult learning inventory among medical students. Education in Medicine Journal, 22-31. 